preparing his contribution to the larger work. Though it has less scope and significance, it does include an account of the ATLAS Computer which was largely developed at Manchester and which introduced the concept of virtual storage in the early 1960 s.

Lavington's early chapters, which attempt to give in a few pages a technical account of the early developments, are rather shaky. However, the style quickly settles down to an interesting description which reinforces and extends the material of the larger book.

S.J. Goldsack is Professor in the Department of Computing at Imperial College, University of London.

\section{IMAGE \\ UNAVAILABLE FOR COPYRIGHT REASONS}

Charles Babbage, 1792-1871, who devised the basic principles of modern computers.

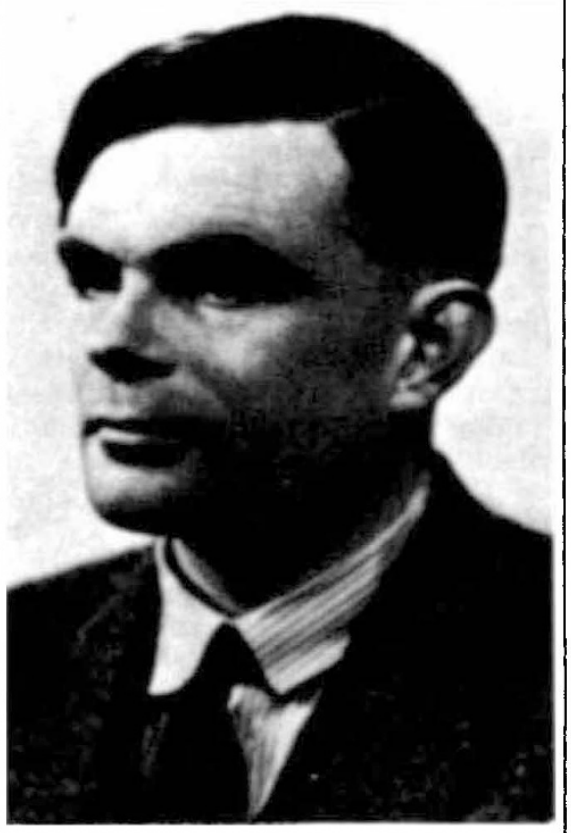

Alan Turing, a leading figure in the early days of computer design. He died in 1954.

Computing and optics in context

\section{P.W. Hawkes}

The Computer in Optical Research. Edited by B.R. Frieden. Pp.371. (SpringerVerlag: 1980.) DM 98, \$57.90.

SOME topics seem so naturally adapted to a multi-author series such as this that when the corresponding volume does appear it is hard to realize that it has no rivals. Frieden's collection is a good example: most of the material is available elsewhere, scattered throughout the literature though not necessarily that of optics, but how very much more useful and usable it becomes, gathered into a single volume, put in context and with a recognizable pattern imposed on it.

Five subject-areas are explored. First, R. Barakat describes the calculation of the various types of integrals that arise in diffraction theory; his aim is to draw attention to the methods that have been developed by numerical analysts, with which specialists in other fields are all too often unfamiliar. This is followed by a long and extremely important chapter by Frieden on probability and statistics. This contains a formal but highly readable account of those aspects of the subjects that Frieden believes to be valuable in optics. After arguing persuasively that such methods are likely to become allpervasive in this field, he regrets that progress is slow since "most optical workers simply do not know the methods" even though "first applications in optics have been highly successful"'. He claims, quite justifiably, that his chapter is the "first exposition on probability and statistics written specifically from the optical perspective and for the optical community".

The remainder of the book is less revolutionary though of considerable interest. A.K. Rigler and R.J. Pegis give a knowledgeable account of optimization methods, L. Mertz examines computers and optical astronomy and W.J. Dallas surveys the computer generation of holograms. Every chapter is filled with practical information, illustrated with numerous examples, and it is clear either that Frieden has submitted the chapters to thorough editing to ensure uniformity of tone or that he chose his contributors very skilfully. Furthermore, he has written an introductory chapter that adds substantially to the usefulness and readability of the remainder. In this, he writes what amounts to a long essay-review of the book, explaining informally how the individual chapters are organized and giving his own opinions of the place of particular approaches in optics. In addition he draws attention, sometimes anecdotally, to other topics that could have been included, or are at too preliminary a stage of development to appear in the main text; Fienup's modified version of the Gerchberg-Saxton algorithm is an example of this.

It is not often that the multi-author formula is entirely satisfactory but here it works to perfection. The best way of recommending this wholly excellent book is to say that I cannot understand how we have been managing without it.

$P$. W. Hawkes is Maitre de Recherches at the Laboratoire d'Optique Electronique du CNRS, Toulouse.

\title{
The double layer in electrochemistry
}

\section{Andrew Hamnett}

The Double Layer. Comprehensive Treatise on Electrochemistry, Vol.1. Edited by J. O'M. Bockris, B.E. Conway and E. Yeager. Pp.453. (Plenum: 1980.) $\$ 49.50, £ 31.19$.

THE Plenum Press have published a remarkable series of books on electrochemistry in recent years, and the Comprehensive Treatise on Electrochemistry is their latest and most ambitious venture. This first volume contains nine articles on aspects of the double layer written by such well-known electrochemists as Parsons, Bockris, Frumkin and Damaskin. Inevitably, these articles make rather varied intellectual demands on the reader, from the considerable in the case of Parsons' introductory article on thermodynamics, to the pedagogically straightforward account by Reeves of the double layer without specific adsorption.

Parsons' account of the Gibbs adsorption isotherm is rightly given the task of introducing this volume. It is an essay of considerable erudition, though the development of the basic equations is very abstract. Some didactic edge is therefore lost in the early part of the essay and only recovered when the author considers some specific examples of electrode configuration.

The two articles by Reeves and by Habib and Bockris constitute the central part of the book. They are both clear and well written, though I would have preferred a more thorough and detailed account of the recent developments in double-layer theory described in Reeves' article. The essay by Bockris and Habib on specific ionic adsorption is a thorough account of a 